\title{
Inter-species Change in Thiobacilli
}

\author{
BY K. I. JOHNSTONE, MARGARET TOWNSHEND \\ AND D. WHITE \\ The Department of Bacteriology and the Houldsworth School of \\ Applied Science, The University, Leeds
}

(Received 2 Augiust 1960)

\section{SUMMARY}

Inter-species conversion has been observed in thiobacilli, starting from isolates of single bacilli.

\section{INTRODUCTION}

Since the early studies on the thiobacilli by Nathansohn (1902) and Beijerinck (1904) work has been directed mainly to the elucidation of their metabolic pathways and their classification. During an investigation into the organisms responsible for the oxidation of sulphur compounds in gas works effluents, an attempt was made to classify the bacteria concerned. It soon became apparent that the classification given by Parker (1957) was inadequate, largely because most of the species had been studied by different investigators using different media and criteria. Several species were therefore obtained from the National Collection of Industrial Bacteria (NCIB) for comparative purposes. A note on the anomalous behaviour of Thiobacillus thioparus NCIB 8870 was published by Townshend \& White (1960); this paper is concerned with the reason for this discrepancy.

\section{METHODS}

Organisms. Two of the organisms used were very similar, and as they closely resemble Thiobacillus neapolitanus. they will be referred to as 'neapolitanus type'. These organisms were: ' $G$ ' which was isolated from a laboratory activated sludge unit treating thiocyanate, and no. 5 which was given by Miss Adams of the National Chemical Laboratory. The other culture used, NCIB 8370, will be referred to in the paper as 8370 .

Culture media. Oxoid Nutrient Agar was used for the nutrient media, and Oxoid Ion Agar no. 2 for the inorganic media, both obtained from Oxo Ltd. London. The various inorganic media used are given in Table 1. Medium S8 was used for anaerobic culture in a McIntosh and Fildes jar.

Stock cultures. These were maintained on S2 agar slopes at $10^{\circ}$ and subcultured every 8 weeks. All incubations were at $30^{\circ}$.

Single organism isolations. These were carried out on the surface of an agar block, using a modification of the technique described by one of us (Johnstone, 1953) with phase contrast illumination. Portions of the block, each carrying a single organism, were transferred to $10 \mathrm{ml}$. amounts of the $\mathrm{S2}$ medium in $50 \mathrm{ml}$. conical flasks. 
Table 1. Composition of inorganic culture media (g./l. distilled water)

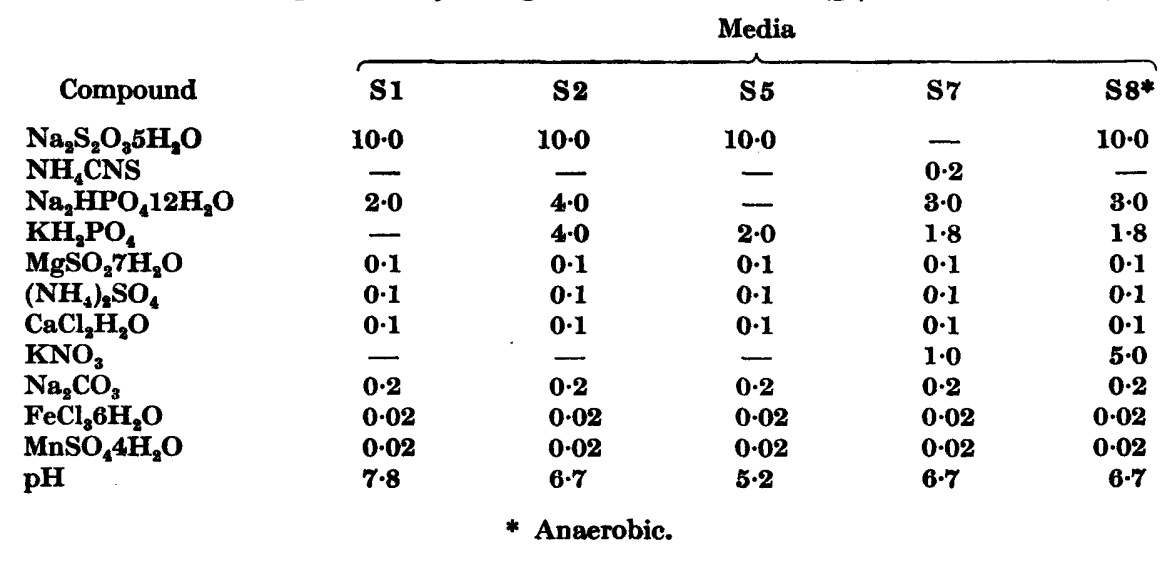

\section{RESULTS}

Experiments with organism ' $G$ '

In the preliminary isolation of organisms from the activated sludge unit, a pure culture was obtained by repeated single colony isolation; it closely resembled Thiobacillus neapolitanus but differed in showing a variable ability to decrease the $\mathbf{p H}$ value. Organism $\mathbf{G}$ was a strictly aerobic autotroph, which decomposed only thiosulphate media, and gave rise to $a$ ' $w$ ' colony type (Table 2). Stock cultures showed colony variants within 2 months. These consisted of two colony types, one a round colourless colony not readily distinguishable from ' $G$ ' except that no sulphur was deposited, and a very thin flat colony with a crenate edge. One or both of these colonies appeared each time ' $G$ ' was re-isolated, but no other colony types were observed. Both these organisms grew on nutrient agar, the round colony type gave rise to a round greyish white colony, and the crenate type to a round opaque grey colony, around which the medium became brown after 7 days. Pure cultures of these organisms grew in thiosulphate liquid medium, but whereas the round colony type used the thiosulphate slowly, the breakdown of thiosulphate by the crenate organism was negligible. Attempts to obtain these variants from the laboratory atmosphere by exposing both liquid and solid media were unsuccessful. Although a mould grew in the liquid medium, no thiobacilli or the colony types described above were ever found.

At this time a culture of Thiobacillus thioparus NCIB 8370, was obtained, which gave unexpected results (Table 2), and an attempt was made to obtain a pure culture of $T$. thioparus from it, by means of single cell technique.

\section{First series of isolation experiments}

In the first series of isolations 8370 was grown on $\mathrm{S2}$ liquid medium and the bacteria isolated during the log phase. The isolates were transferred to the S2 medium, and subcultured thence to various test media (Table 2). As may be seen from Table 2, seven of the twelve isolates grew, five of those within 5 days and a further two (I.7 and I.12) after 2 weeks. Four types of bacteria were dis- 
Table 2. Character of the isolates from NCIB 8370 (series 1)

\begin{tabular}{|c|c|c|c|c|c|c|c|c|c|c|}
\hline \multirow{2}{*}{$\begin{array}{l}\text { Isolate } \\
\text { no. }\end{array}$} & \multicolumn{4}{|c|}{$\begin{array}{l}\text { Loss of sulphur } \\
\text { compound in } \\
\text { liquid media }\end{array}$} & \multicolumn{5}{|c|}{$\begin{array}{c}\text { Growth on agar plates } \\
\text { ( } 2 \% \text { agar) }\end{array}$} & \multirow{2}{*}{$\begin{array}{c}\text { Colony* } \\
\text { type }\end{array}$} \\
\hline & S1 & S2 & S5 & S7† & s1 & S2 & S5 & S8 & Nutrient & \\
\hline I.4 & + & + & + & + & + & - & + & - & - & w \\
\hline I. 6 & - & - & - & - & + & + & + & + & + & $\mathbf{r}$ \\
\hline I. 7 & + & + & + & + & + & - & + & + & - & w \\
\hline I. 8 & - & - & - & - & + & + & + & + & + & $r+c$ \\
\hline I.9 & + & + & + & + & + & + & + & + & + & $\mathbf{r}+\mathrm{c}+\mathrm{w}$ \\
\hline I. 10 & + & + & + & + & + & + & + & + & + & $\mathbf{r}+\mathbf{w}$ \\
\hline I. 12 & + & + & + & + & + & - & + & + & - & $\mathbf{w}$ \\
\hline Original & + & + & - & - & + & + & - & + & + & $\mathbf{w}$ \\
\hline
\end{tabular}

* Colony types: $w=$ round colony which deposited sulphur; $r=$ round colony which did not deposit sulphur; $c=$ crenate-edged colony which did not deposit sulphur.

† Thiocyanate.

‡ Anaerobic.

tinguishable by the test media used, I.4 (' $w$ ' colony type, strict aerobe) I.6 (' $r$ ' colony type, facultative anaerobe) 1.7 (' $w$ ' colony type facultative anaerobe), crenate organism (' $c$ ' colony type, strict aerobe). The distribution of the three colony types on various solid media (Table 3 ) shows clear differences between the four organisms. I.4 and I. 7 were strictly autotrophic thiobacilli with similar colonial appearance, which decomposed thiosulphate and thiocyanate, but which differed in I. 7 's ability to grow anaerobically. I. 6 was a heterotroph and a facultative anaerobe, which decomposed thiosulphate slowly. The crenate colony type was strictly aerobic and a heterotroph.

Table 3. Colony types appearing on the agar plates (Series 1)

\begin{tabular}{|c|c|c|c|c|c|}
\hline \multirow[b]{3}{*}{ Isolate no. } & \multicolumn{5}{|c|}{ Media } \\
\hline & \multicolumn{5}{|c|}{ Colony type } \\
\hline & S1 & S2 & S5 & S8 & Nutrient \\
\hline I.4 & $\mathbf{w}$ & - & $\mathbf{w}$ & 一 & - \\
\hline I.6 & $\mathbf{r}$ & $\mathbf{r}$ & $\mathbf{r}$ & $\mathbf{r}$ & $\mathbf{r}$ \\
\hline I.7 & $\mathbf{w}$ & - & $\mathbf{w}$ & $\mathbf{w}$ & - \\
\hline I.8 & $\mathbf{r}+\mathbf{c}$ & $\mathbf{r}+\mathbf{c}$ & $\mathbf{r}+\mathbf{c}$ & $\mathbf{r}$ & $\mathbf{r}+\mathbf{c}$ \\
\hline I.9 & $\mathbf{r}+\mathbf{c}+\mathbf{w}$ & $\mathbf{r}+\mathbf{c}$ & $r+c+w$ & $\mathbf{r}$ & $\mathbf{r}+\mathbf{c}$ \\
\hline $\mathbf{I . 1 0}$ & $\mathbf{r}+\mathbf{w}$ & $\mathbf{r}$ & $\mathbf{r}+\mathbf{w}$ & $\mathbf{r}$ & $\mathbf{r}$ \\
\hline I.12 & $\mathbf{w}$ & - & $\mathbf{w}$ & $\mathbf{w}$ & - \\
\hline
\end{tabular}

The most interesting aspect of this work was that in three cases a single bacterium had given rise to more than one type of organism. In addition, the two organisms which did not deposit sulphur on the plates were very similar to the variants found previously with ' $G$ '. At this time the stock cultures of 8370 and ' $G$ ' were again tested, and 8370 had acquired the ability to decompose thiocyanate, thus paralleling the changes found in the isolates. ' $G$ ' also utilized thiocyanate, and the two stock cultures now appeared to be identical, each growing on all the test media and exhibiting the three colony types. 
Table 4. Characteristics of the isolates from 8370 and organism no. 5 (series 2)

\begin{tabular}{|c|c|c|c|c|c|c|c|c|c|c|}
\hline \multirow{2}{*}{$\begin{array}{c}\text { Isolate } \\
\text { no. } 8370\end{array}$} & \multicolumn{4}{|c|}{$\begin{array}{l}\text { Loss of sulphur } \\
\text { compound in } \\
\text { liquid media }\end{array}$} & \multicolumn{5}{|c|}{ Growth on agar plates } & \multirow{2}{*}{$\begin{array}{r}\text { Colony } \\
\text { type }\end{array}$} \\
\hline & $\mathbf{S} 1$ & $\mathbf{S 2}$ & S5 & sty & S1 & S2 & S5 & S8t & Nutrient & \\
\hline II. 1 & - & - & - & - & + & + & - & + & + & $\mathbf{r}$ \\
\hline II. 8 & - & - & - & - & + & + & - & + & + & $\mathbf{r}$ \\
\hline II.4 & - & - & - & - & + & + & - & - & + & c \\
\hline II.5 & + & + & + & + & + & + & - & - & - & $\mathbf{w}$ \\
\hline II. 6 & +8 & - & - & - & - & - & - & - & - & w8 \\
\hline II.7 & + & + & + & + & + & + & - & - & - & $\mathbf{w}$ \\
\hline II. 8 & +8 & - & - & - & + & + & - & + & + & $\mathbf{r}+\mathbf{w s}$ \\
\hline II. 9 & - & - & - & $+\S$ & + & + & - & + & + & $r+w$ \\
\hline $\begin{array}{c}\text { Original } \\
\text { culture } \\
\mathbf{8 3 7 0}\end{array}$ & + & + & - & + & + & + & - & + & + & $c+r+$ \\
\hline No. 5 & & & & & & & & & & \\
\hline II. 12 & + & + & + & - & + & + & + & - & - & $\mathbf{w}$ \\
\hline II. 13 & + & + & + & - & + & + & + & - & - & $\mathbf{w}$ \\
\hline II. 14 & + & + & + & - & + & + & + & - & - & $\mathbf{w}$ \\
\hline II. 16 & + & + & + & - & + & + & + & - & - & $\mathbf{w}$ \\
\hline II.17 & + & + & + & - & + & + & + & - & - & $\mathbf{w}$ \\
\hline II. 19 & + & + & + & - & + & + & + & - & - & $\mathbf{w}$ \\
\hline $\begin{array}{c}\text { Original } \\
\text { culture } \\
\text { no. } 5\end{array}$ & + & + & + & - & + & + & + & - & - & $\mathbf{w}$ \\
\hline
\end{tabular}

* Colony types: $w=$ round colony which deposited sulphur; $r=$ round colony which did not deposit sulphur; $c=$ crenate-edged colony which did not deposit sulphur.

$\uparrow$ Thiocyanate.

$\ddagger$ Anaerobic.

8 Grew after 16 days in the liquid media only.

\section{Second series of isolation experiments}

In this series 8370 and no. 5 (a neopolitanus type organism which had been maintained in these laboratories for 5 months without showing any colony variation) were used. The characteristics of the stock cultures were tested immediately before isolation and ten isolates were made from each culture (Table 4). Of the ten isolates from 8370, seven grew within 1 week and each was a pure culture. After 2 weeks a further organism II. 6 was found to be growing, and at this time II. 8 and II.9 were found to contain two types of organisms giving no subculture $r$ and $w$ colonies. In each case the later occurring $w$ colonies were shown to use thiocyanate and were I.4 of the previous experiment. Six of the isolated bacteria from no. 5 grew; each was a pure culture with the characteristics of the parent strain.

\section{DISCUSSION}

The conclusive evidence that these organisms may change comes from the first series of isolations in which four changes were observed; in two instances a single bacterium gave rise to a mixture of two organisms, and in one case a mixture of three occurred. 
The second series confirmed these results with two more examples; but additional evidence is also available from the behaviour of the stock cultures of ' $G$ ' and 8870 . The original culture of $\mathbf{8 8 7 0}$ did not decompose thiocyanate, despite the many experiments which were made in attempts to confirm the findings of De Kruyff, van der Walt \& Schwartz (1957) on this point. Four months later, when the isolations were made, two distinct organisms were found, each of which decomposed thiocyanate, neither of which could have been present in the original culture. In view of this evidence the authors believe that single organisms of some strains of thiobacilli can give rise to the range of organisms described in this paper.

The evidence against contamination is strong. The variants were never found in liquid or solid media exposed in the laboratory and the fact that culture no. 5 has not changed over the same period of time suggests that contamination is not the cause. Of the four stock cultures maintained in these laboratories two have changed and two have not, which suggests that the cause is not environmental, but is inherent in the organisms. This evidence suggests that the change is genetic rather than adaptive, especially when it is recalled that organisms which have arisen can utilize thiocyanate, to which they have not been exposed in the laboratory.

The media chosen for these experiments clearly distinguish four organisms. Two of these, I.4 and I.7, are strictly autotrophic thiobacilli, and I.6 corresponds to Thiobacillus trautweinii, which uses thiosulphate slowly under aerobic and anaerobic conditions. As the crenate organism did not use thiosulphate, it would not be classed as a thiobacillus, despite its close relationship to this group. Using the criteria given by Parker (1957), the organisms described may be regarded as distinct species; on these grounds inter-species change may be said to have occurred.

From the stock culture ' $G$ ', which was originally a strictly autotrophic strain, both heterotrophs and autotrophs have arisen. These results support the suggestion of Vishniac \& Santer (1957) that there is little fundamental difference in this group between autotrophic and heterotrophic metabolism, and we have shown that these thiobacilli can change relatively easily from one mode of life to the other. This interconversion of species of Thiobacillus explains the results which we originally found with NCIB 8370. For the same reason, it is possible that De Kruyff, van der Walt \& Schwartz (1957), using NCIB 8370, were working with I.7 organisms.

The authors wish to thank Professor F. C. Happold of this University, and the late Miss M. E. Adams of the National Chemical Laboratory, for helpful discussion, and the Joint Research Committee of the Gas Council for permission to publish this paper.

\section{REFERENCES}

Beijerinck, M. W. (1904). Phénomènes de reduction produits par les microbes. Arch. néerl. Sci. Sér. 2, 9, 181.

Bergey's Manual of Determinative Bacteriology (1957), 7th ed. Ed. R. S. Breed, E. G. D. Murray and N. R. Smith. London: Ballière, Tindall and Cox.

JoHnstone, K. I. (1953). Micromanipulation on an agar surface for the isolation of single organisms. J. gen. Microbiol. 9, 293. 
Kroyff, C. D. DE, van der Walt, J. P. \& Schwartz, H. M. (1957). The utilization of thiocyanate and nitrate by thiobacilli. Leevwoenhoek ned. Tijdschr. 23, 305.

Nathansonn, A. (1902). Uber eine neue Gruppe von Schwefelbakterien und ihren Stoffwechsel. Mitt. zool. Sta. Neapel, 15, 665.

Parker, C. D. (1957). In Bergey's Manual of Determinative Bacteriology, 7th ed. p. 83. London: Ballière, Tindall and Cox.

Townshend, M. \& Whrm, D. (1960). Characteristics of Thiobacillus thioparus. Nature, Lond. 185, 870.

Vishniac, W. \& Santer, M. (1957). The thiobacilli. Bact. Rev. 21, 195. 